\title{
Measurement properties of the Danish version of the Awareness and Beliefs about Cancer $(A B C)$ measure
}

Line Hvidberg ${ }^{1,2^{*}}$, Anette Fischer Pedersen ${ }^{1}$, Christian Nielsen Wulff' ${ }^{3}$ Anders Helles Carlsen ${ }^{1}$ and Peter Vedsted ${ }^{1}$

\begin{abstract}
Background: The International Cancer Benchmarking Partnership aims to study international differences in cancer survival and the possible causes. Participating countries are Australia, Canada, Norway, Sweden, Denmark and the UK and a particular focus area is differences in awareness and beliefs about cancer. In this connection, the Awareness and Beliefs about Cancer (ABC) measure has been translated into multiple languages. The aim of this study is to appraise the translation process and measurement properties of the Danish version of the $A B C$ measure.
\end{abstract}

Methods: The translation process included forward and backward translations and a pilot-test. Data quality was assessed using survey data from 3000 Danish respondents and content validity indexes were calculated based on judgments from ten academic researchers. Construct validity was determined by a confirmative factor analysis (CFA) and exploratory factor analyses (EFA) using survey data and a known group comparison analysis including 56 persons. Test-retest reliability was assessed based on responses from 123 person whom completed the interview twice with an interval of 2-3 weeks.

Results: The translation process resulted in a Danish $A B C$ measure conceptually equivalent to the English $A B C$ measure. Data quality was acceptable in relation to non-response to individual items which was maximum 0.3\%, but the percentage of respondents answering 'don't know' was above 3\% for 16 out of 48 items. Content validity indexes showed that items adequately reflected and represented the constructs to be measured (item content validity indexes: 0.9-1.0; construct content validity indexes: 0.8-1.0). The hypothesised factor structure could not be replicated by a CFA, but EFA on each individual subscale showed that six out of seven subscales were unidimensional. The ABC measure discriminated well between non-medical academics and medical academics, but had some difficulties in discriminating between educational groups. Test-retest reliability was moderate to substantial for most items.

Conclusions: The Danish ABC measure is a useful measurement that is accepted and understood by the target group and with accepted measurement criteria for content validity and test-retest reliability. Future studies may further explore the factorial structure of the $A B C$ measure and should focus on improving the response categories.

Keywords: Cancer, Awareness, Beliefs, Data quality, Validity, Reliability, Factor analysis, Known group comparison

\footnotetext{
* Correspondence: LINE.HVIDBERG@PH.AU.DK

${ }^{1}$ Research Centre for Cancer Diagnosis in Primary Care (CaP), Research Unit

for General Practice, Department of Public Health, Aarhus University,

Bartholins Allé 2, 8000 Aarhus C, Denmark

${ }^{2}$ Section for General Medical Practice, Department of Public Health, Aarhus

University, Bartholins Allé 2, 8000 Aarhus C, Denmark

Full list of author information is available at the end of the article
}

(c) The Author(s). 2017 Open Access This article is distributed under the terms of the Creative Commons Attribution 4.0 International License (http://creativecommons.org/licenses/by/4.0/), which permits unrestricted use, distribution, and reproduction in any medium, provided you give appropriate credit to the original author(s) and the source, provide a link to the Creative Commons license, and indicate if changes were made. The Creative Commons Public Domain Dedication waiver (http://creativecommons.org/publicdomain/zero/1.0/) applies to the data made available in this article, unless otherwise stated. 


\section{Background}

During the last two decades, several studies have shown that the United Kingom (UK) and Denmark have higher cancer incidence and lower survival than other highincome countries [1-3]. In response, the International Cancer Benchmarking Partnership (ICBP) was launched in 2009 to study variations related to cancer survival between Australia, Canada, Norway, Sweden, Denmark and the UK [4]. A particular focus area is differences in awareness and beliefs about cancer, as a possible contributor to the observed differences in cancer survival. In this connection, the Awareness and Beliefs about Cancer (ABC) measure was developed [4], which is an extension of the Cancer Awareness Measure (CAM) [5]. The new items have been adapted from population-based surveys and from studies on cancer beliefs, screening uptake and healthcare seeking [6-8].

The target population for the $\mathrm{ABC}$ measure is the adult general population in the participating ICBP countries and the $\mathrm{ABC}$ measure was developed to be administered by telephone interview. The measurement aim of the $\mathrm{ABC}$ measure is discriminative, thus to differentiate between countries and socio-economic groups in terms of awareness and beliefs about cancer.

The English ABC measure has shown to have acceptable content validity and test-retest reliability, and much effort have been made to obtain conceptual and cultural equivalent Danish, Swedish, Norwegian and Canadian French translations of the ABC measure [4]. However, as noted by Simon et al. [4], measurement properties of the $\mathrm{ABC}$ measure need to be established in each country where it is used. Thus, the aims of this study are:

1) To describe the translation process from the English to the Danish ABC measure.

2) To evaluate the data quality of the Danish $A B C$ measure.

3) To evaluate content and construct validity and test-retest reliability of the Danish $\mathrm{ABC}$ measure.

\section{Methods}

The translation process and appraisal of the measurement properties can be divided into five steps: (1) translation, (2) data quality, (3) content validity, (4) construct validity and (5) test-retest reliability. An overview of participants in each step is shown in Fig. 1.

\section{Translation}

To achieve a Danish version conceptually equivalent to the English $\mathrm{ABC}$ measure the translation was conducted in agreement with the guidelines for translation procedures suggested by de Vet et al. [9]. It involved forward and backward translations with consensus meetings and a pilot-test.

\section{Forward translation}

Forward translations were performed independently by two native speakers of Danish; one professional translator and one with familiarity with the cancer research area. Based on a consensus meeting with the translators and experts in the cancer area on awareness and beliefs, one reconciled forward version was formed.

\section{Backward translation}

The reconciled version was back-translated by two native English-speaking persons who were fluent in Danish. The translations were performed independently of each other. Following the back-translation, both translators were provided with the original English version and on a consensus meeting discrepancies between the translations and potential cross-cultural issues were discussed to obtain conceptually equivalent versions of the original English and the Danish ABC measure. The results of the translation were dicussed with the English ICBP group before a pre-final Danish ABC version was made.

\section{Pilot-test}

The pilot-test took place at the Department of Orthopedic Surgery (foot/ankle and spine sectors) at Aarhus University Hospital. We assumed that persons hospitalised here could use the requested time for an interview and that we would be able to obtain interviews with persons from diverse groups in terms of age, gender, marital status, education and occupation. Hence, three women and five men aged 43-77 years with diverse socio-economic characteristics participated in the pilot-test by means of face-to-face interviews.

First, the interviewer read the related introduction and item to the participants and subsequently methods such as think-aloud and probing were used e.g. "How did you reach the number of days in relation to how long it would take you to go to the doctor?" and "Can you tell me in your own words what you understand by any breast changes?". Also, participants' elaborations on difficulties in answering and anything else that shed light on the acceptability and understanding of the measure was noted by the interviewer. The length of the interviews was approximately $1 \mathrm{~h}$.

\section{Data quality}

Data quality reflects respondents' understanding and acceptance of the items [10]. Data quality was assessed using the Danish data from the ICBP survey. The data collection is described briefly here and for further details see Hvidberg et al. [11]. Between 31 May and 4 July 2011, 3000 Danish residents aged 30 years or older answered the 20-min computer-assisted ABC telephone interview. The respondents' mean age was 56 years (range 30-99 years) and the majority were women (55\%), married/cohabiting $(77 \%)$ and in the labour force $(63 \%)$. This 


\section{Translation}

Pilot-test with eight persons aged 43-77 years; three women and five men.

\section{Data quality}

Telephone interviews with 3,000 respondents $(1,000$ respondents aged $30-49$ years and 2,000 respondents aged 50 years or older) randomly selected from a representative sample of the Danish population from the Danish Civil Registration System (CRS).

\section{Content validity}

Ten academic researchers were asked to assess whether items were relevant and comprehensive for the constructs meant to be measured.

\section{Construct validity}

Confirmatory and exploratory factor analyses: The 3,000 respondents who participated in the nationwide survey.

Hypothesis testing ('Known group comparison'): Three groups included: a) 16 bluecollar workers from the Building Services at Aarhus University; b) 21 academics from departments at Aarhus University and c) 19 GP's, and doctors at Department of Oncology at Aarhus University Hospital.

\section{Test-retest reliability}

123 persons participated in the test-retest ( 55 persons in the age group 30-40 years of age and 68 persons between the ages of $60-70$ years).

Fig. 1 Overview of participants in the study

information was obtained through individual linkage to Statistics Denmark [12].

For each item the percentage of respondents answering 'don't know' or not answering at all was examined. Less than 3\% was considered acceptable [9]. Further, the distribution of responses for each item was examined. Items for which more than $95 \%$ of all respondents answered in the same response category was considered to have poor discriminative ability [13].

\section{Content validity}

Content validity assessment examines the degree to which the items adequately reflect and comprehensively represent the construct to be measured [9]. The content validity assessment was based on judgments from ten academic researchers, which is believed to be a sufficient number to provide a sufficient level of control for chance agreement [14]. The researchers had a background in Psychology, Public Health Science or Medicine and had expertise in creating and validating measurements and in cancer and public health research. The content validity assessment was carried out in November 2014.

The content validity index (CVI) was used [14, 15] consisting of the 'item CVI' (I-CVI) and 'construct CVI' (C-CVI). To calculate the I-CVI, the raters were asked to rate the relevance of each item on a 4-point scale (1: not relevant, 2: somewhat relevant, 3: quite relevant, 4: highly relevant) [15]. Raters were asked for additional comments if they scored an item 1 or 2 . For each item, the I-CVI was computed as the number of raters giving a rating of 3 or 4 , divided by the total number of raters. Thus, an item rated as 'quite relevant' or 'highly relevant' by eight out of ten raters would have an I-CVI of 0.80 and an I-CVI of $\geq 0.80$ was considered acceptable for content validity to be established in this study [14].

For calculating C-CVI, the raters were asked to rate the degree to which each construct was covered by the given items on a 4-point scale (1: to a very low degree, 2: to a low degree, 3: to some degree, 4: to a high degree). The same method and criterion as for I-CVI was used for the C-CVI.

\section{Construct validity}

The core $\mathrm{ABC}$ measure includes the following five subscales: anticipated patient interval for healthcare seeking (4 items); awareness of cancer symptoms ( 1 recall item and 11 recognition items) [16]; anticipated barriers for healthcare seeking (4 items); beliefs about cancer (6 items) and awareness of 5-year survival from cancer (4 items). Denmark and some of the other countries from the ICBP included three additional subscales, i.e. beliefs about breast cancer screening (3 items for women only); beliefs about bowel cancer screening (3 items) and awareness of risk factors for cancer (13 recognition items). For this study, construct validity was evaluated by assessing two aspects: structural validity and hypotheses testing [9]. 


\section{Structural validity}

Structural validity, i.e. the degree to which the scores on the measure are an adequate reflection of the dimensionality of the construct [9]. The data from the 3000 respondents was used. First, Confirmative Factor Analysis (CFA) was performed as we had a priori hypotheses about which items belonged to which factor. Next, Exploratory Factor Analysis (EFA) was used on the individual subscales to test the extent to which the items in each subscale appeared to represent the same underlying construct.

The subscale 'awareness of 5-year survival from cancer' was not included in neither the CFA nor the EFA as these four items are not expected to correlate, as respondents are asked to state how many out of 10 persons are alive after 5 years for four very different types of cancer.

The following three fit indices were applied for CFA and EFA: The root mean square error of approximation (RMSEA; acceptable values $<0.05$ ), the comparative fit index (CFI; acceptable fit $>0.90$ and preferable fit $>0.95$ ) and the Tucker-Lewis Index (TLI; acceptable fit $>0.90$ and preferable fit $>0.95$ ) [17]. For EFA, oblique rotation was chosen to clarify the data structure and factors were assessed by examine multiple criteria i.e. the Kaiser-Guttman eigenvalues $>1$ rule, the scree plot, the factor loading criteria of 0.3 and interpretability of resulting factors. Also crossloadings of 0.3 or higher were assessed $[17,18]$. The CFA and EFA were conducted using the WLSMV estimator in Mplus Version 7.4 [19].

\section{Hypotheses testing}

We tested predefined hypotheses about differences in awareness and beliefs about cancer between different groups regarding educational level or medical proficiency. Three groups were included for this known group comparison': 1) blue-collar workers at Building Service at Aarhus University; 2) academics at departments at Aarhus University 3) general practitioners (GP's) and doctors at Department of Oncology at Aarhus University Hospital. All were invited by e-mail and were asked to write back if they agreed to participate. Subsequently, a day and time was arranged where they were called to answer the ABC measure. The data was collected by three unaffiliated trained interviewers between November 2012 and January 2014.

Comparison between groups was made on items where differences were expected based on the literature on awareness and beliefs about cancer [5, 20-24]. Thus, the hypotheses had been formulated a priori based on previous research among different socioeconomic groups in the general population and based on comparisons between cancer experts and non-medical academics [5, 20-24]. Differences in proportions between groups were tested using Fisher's Exact Test. The statistical significance level was set to 0.05 or less.
The following hypotheses were tested:

Group 1 vs. 2:

I. Awareness of cancer symptoms: Group 2 was expected to be significantly more aware that unexplained bleeding can be a sign of cancer.

II. Anticipated barriers for healthcare seeking: Group 2 was expected to be significantly more likely to concur that being too busy to make time to go to the doctor is a barrier to healthcare seeking.

III.Awareness of risk factors for cancer: Group 2 was expected to be significantly more aware of the risk factor 'having a close relative with cancer'.

IV.Awareness of risk factors for cancer: Group 2 was expected to be significantly more aware of the risk factor 'getting sunburnt more than once as a child'.

Group 2 vs. 3:

I. Awareness of cancer symptoms: Group 3 was expected to be significantly more aware that a sore that does not heal can be a sign of cancer.

II. Awareness of 5-year survival from cancer: Group 3 was expected to be significantly more likely to correctly identify the 5-year survival from ovarian cancer.

III.Awareness of risk factors for cancer: Group 3 was expected to be significantly more likely to correctly identify that cancer risk is higher in people aged 70 -years than at a younger age.

IV.Awareness of risk factors for cancer: Group 3 was expected to be significantly more likely to correctly identify that 'infection with human papillomavirus (HPV)' is a risk factor for cancer.

We used the criterion by Terwee et al. [10] that confirmation of at least $75 \%$ of the hypotheses indicates sufficient construct validity.

\section{Test-retest reliability}

The reproducibility, i.e. the degree to which scores are stable over time when the factors underlying the measure have not changed, was assessed with a test-retest [9]. We contacted individuals aged $30-40$ years and 60-70 years, who were randomly selected among persons who had not participated in the nationwide survey, but who had been eligible for participation [11]. The ABC measure was completed twice with an interval of 2-3 weeks in the period from March to June 2012. The interval was chosen as an adequate time interval for respondents not to precisely recall their previous responses to the items and for their awareness and beliefs about cancer not to have radically changed between the two occasions. A transition question was included at the end of the retest interview asking whether respondents themselves thought that 
their awareness and beliefs about cancer had changed since the first interview. If transition had taken place, the respondent was excluded from the test-retest analyses.

A total sample size of 100 persons was determined as reasonable for the test-retest [9]. The test-retest was undertaken by two unaffiliated trained interviewers. The openended recall question on symptoms of cancer was not assumed to be stable between test and retest because this question was asked before the 11 closed recognition items on awareness of cancer symptoms.

Test-retest reliability was calculated as the unweighted Cohen's kappa for nominal items and the quadratic weighted kappa coefficient for ordinal items. Kappa coefficients were interpreted according to Landis and Koch: $<0.00$ as poor, $0.00-0.20$ as slight, $0.21-0.40$ as fair, $0.41-0.60$ as moderate, $0.61-0.80$ as substantial and $0.81-1$ as almost perfect agreement [25].

For awareness of cancer symptoms and risk factors for cancer aggregated continuous scores were also computed as papers on the CAM and the ABC measure commonly report a total score of correctly identified symptoms and risk factors [4, 5, 20]. For awareness of cancer symptoms a score of 1 point was given for the answer 'yes' and 0 for the answer 'no' (possible range of aggregated score: $0-11$ ). For awareness of risk factors for cancer the answers 'tend to agree' and 'strongly agree' were given 1 point and 'strongly disagree' and 'tend to disagree' were given 0 points (possible range of aggregated score: $0-13$ ). The intraclass correlation coefficient (ICC) with 95\% CI was computed for the total number of symptoms and risk factors recognised using a two-way random effect model measuring absolute agreement $\left(\mathrm{ICC}_{2,1}\right.$ according to Shrout and Fleiss [26]). Guidelines for the interpretation of ICC suggest that a value $>0.70$ is acceptable [9]. Subgroup analyses were performed to assess consistency of the kappa coefficients and the ICCs across the two age strata, $30-40$ and $60-70$ years of age.

\section{Results}

\section{Translation}

\section{Final version}

The comprehensive translation procedures resulted in a Danish $\mathrm{ABC}$ measure that was found to be conceptually equivalent to the English $\mathrm{ABC}$ measure. As a consequence of the pilot-test the introduction to the $\mathrm{ABC}$ measure was shortened and explanations of some terms were needed (e.g. processed meat). These alterations were incorporated in both the original English version and the Danish version of the ABC measure. Documentation of the translation process is available upon request.

\section{Data quality}

The percentage of respondents answering 'don't know' for each item ranged from 0 to $68.3 \%$ and was nonacceptable (above 3\%) for 16 out of 48 items (only one item was $>10 \%$ ). The data quality for the 16 items is seen in Table 1 (the data quality for all 48 items can be found in Additional file 1, available online). Non-response to individual items was maximum $0.3 \%$. All items, except for one had acceptable discriminative ability. The item with poor discriminative ability was 'Change in the appearance of a mole' as it was recognised as a possible sign of cancer by $97.2 \%$ of all respondents (data not shown).

\section{Content validity}

The majority of the items received high ratings from the ten raters in terms of being relevant for the construct to be measured. Thus, the I-CVI ranged from 0.9 to 1.0. Also, the comprehensiveness of each construct $(\mathrm{C}-\mathrm{CVI})$ was given a high rating, ranging from 0.8 to 1.0. The construct given the lowest C-CVI was 'anticipated patient interval for healthcare seeking' (data not shown).

\section{Construct validity \\ Structural validity}

The hypothesised seven factor structure of the $\mathrm{ABC}$ measure showed a good fit for the RMSEA indice and a poor fit for the other two indices. The indices for model fit were 0.032, 0.864 and 0.854 for RMSEA, CFI and TLI, respectively. Sub-group analyses were performed for men and women separately, because items about breast cancer were only answered by women. This did not change the fit indices significantly.

EFAs on each individual subscale revealed that six out of seven subscales were unidimensional based on the evaluation of eigenvalues, the scree plot, factor loadings and the interpretability of the factors. The subscale that was not unidimensional was 'Beliefs about cancer', which showed a two-factor structure as two of its items ('Q29. Most cancer treatment is worse than the cancer itself' and 'Q30. Not want to know if I have cancer') loaded onto a second factor. Item 'Q33. A diagnosis of cancer is a death sentence' also cross-loaded onto this second factor. Considering this and the interpretability of the factor structure it is advocated that the 'beliefs about cancer' subscale are split into 'positive beliefs about cancer' (item Q28, Q31, Q32) and 'negative beliefs about cancer' (item Q29, Q30, Q33). Table 2 presents the results of the EFAs with factor loadings and crossloadings of 0.3 or higher for each item and the goodness of fit indices for each factor. 
Table 1 Data quality: Number of respondents who 'did not answer' and who answered 'don't know'. Only items with $>3 \%$ of respondents answering 'don't know' are shown. Total $n=3000$ for all items

\begin{tabular}{|c|c|c|}
\hline & $\begin{array}{l}\text { Did not } \\
\text { answer } \\
\%(n)\end{array}$ & $\begin{array}{l}\text { Don't know }{ }^{a} \\
\%(n)\end{array}$ \\
\hline \multicolumn{3}{|l|}{ Awareness of cancer symptoms } \\
\hline \multicolumn{3}{|l|}{ Response options: yes; no. } \\
\hline Q10. Persistent unexplained pain & $0(0)$ & $3.4(101)$ \\
\hline Q11. Unexplained bleeding & $0(0)$ & $4.5(135)$ \\
\hline Q14. Persistent difficulty in swallowing & $0(0)$ & $3.4(101)$ \\
\hline Q16. Sore that does not heal & $0(1)$ & $4.5(134)$ \\
\hline Q17. Unexplained night sweats & $0(0)$ & $8.2(245)$ \\
\hline \multicolumn{3}{|l|}{ Beliefs about cancer } \\
\hline \multicolumn{3}{|l|}{$\begin{array}{l}\text { Response options: strongly disagree; } \\
\text { tend to disagree; tend to agree; } \\
\text { strongly agree. }\end{array}$} \\
\hline $\begin{array}{l}\text { Q29. Most cancer treatment is } \\
\text { worse than the cancer itself }\end{array}$ & $0.3(8)$ & $9.9(296)$ \\
\hline \multicolumn{3}{|l|}{ Awareness of 5-year survival from cancer } \\
\hline \multicolumn{3}{|l|}{ Response options: $0 ; 1 ; 2 ; 3 ; 4 ; 5 ; 6 ; 7 ; 8 ; 9 ; 10}$. \\
\hline $\begin{array}{l}\text { Q34. Out of } 10 \text { people diagnosed } \\
\text { with bowel cancer, how many do } \\
\text { you think would be alive } 5 \text { years later? }\end{array}$ & $0.1(3)$ & $5.0(151)$ \\
\hline $\begin{array}{l}\text { Q36. Out of } 10 \text { people diagnosed with } \\
\text { ovarian cancer, how many do you think } \\
\text { would be alive } 5 \text { years later? }\end{array}$ & $0.2(5)$ & $6.3(189)$ \\
\hline $\begin{array}{l}\text { Q37. Out of } 10 \text { people diagnosed } \\
\text { with lung cancer, how many do } \\
\text { you think would be alive } 5 \text { years later? }\end{array}$ & $0.2(5)$ & $3.1(93)$ \\
\hline \multicolumn{3}{|l|}{ Awareness of risk factors for cancer } \\
\hline \multicolumn{3}{|l|}{$\begin{array}{l}\text { Response options: strongly disagree; } \\
\text { tend to disagree; tend to agree; } \\
\text { strongly agree }\end{array}$} \\
\hline $\begin{array}{l}\text { QN3. Drinking more than } 1 \text { unit of } \\
\text { alcohol a day }\end{array}$ & $0(0)$ & $3.1(94)$ \\
\hline $\begin{array}{l}\text { QN5. Eating red or processed meat } \\
\text { once a day or more }\end{array}$ & $0(1)$ & $7.5(224)$ \\
\hline QN6. Being obese & $0(1)$ & $4.1(124)$ \\
\hline QN8. Being over 70 years old & $0(1)$ & $3.2(96)$ \\
\hline QN9. Having a close relative with cancer & $0.1(2)$ & $3.1(94)$ \\
\hline $\begin{array}{l}\text { QN10. Infection with HPV, Human } \\
\text { Papillomavirus }\end{array}$ & $0(0)$ & $68.3(2050)$ \\
\hline $\begin{array}{l}\text { QN13. Exposure to ionising radiation from, for } \\
\text { example, radioactive materials, } x \text {-rays or radon }\end{array}$ & $0.1(2)$ & $3.8(114)$ \\
\hline
\end{tabular}

${ }^{a}$ Don't know was not provided as a response option in any items, but was noted by the interviewer when respondents answered 'don't know' unprovokedly

\section{Hypotheses testing}

In total, 59 persons participated. Three persons which should represent the blue-collar group had first or second stage of tertiary education and where therefore excluded. Ultimately, 56 persons were included in the analysis: 16 blue-collar workers from the Building Service (group 1), 21 academics from departments at Aarhus University (group 2) and 19 GP's and oncologist (group 3). The mean ages of the three groups were 54, 46 and 50 years for group 1, 2 and 3, respectively. A majority of group 3 were men (74\%) compared to 63 and $52 \%$ in group 1 and 2, respectively. Group 3 had considerably fewer close relatives with cancer (68\%) than group 1 (94\%) and group 2 (91\%).

Table 3 displays the results of the hypothesis testing. When the two different educational groups (group 1 vs. group 2) were compared three out of four of the hypotheses tested differed in the expected direction, but only one out of four differed statistically significantly. When non-medical and medical academics (group 2 vs. group 3) were compared all of the hypotheses tested differed in the expected direction and three out of four (75\%) of the hypotheses differed statistically significantly.

\section{Test-retest reliability}

Figure 2 shows the flowchart for test-retest. Of 362 persons approached for participation in the test-retest, 138 (38\%) persons answered both the test and the retest. Fifteen persons were excluded as they reported a change in their awareness and/or beliefs about cancer leaving 123 persons $(34 \%)$ for the analyses.

Results of the test-retest reliability are shown in Table 4. The percentage of agreement between test and retest ranged from 77.6 to $100 \%$ with 48 out of 56 items having an agreement of $>90 \%$. The kappa coefficient ranged from -0.01 (change in the appearance of a mole) to 1 (bowel cancer screening behavior) and most of the kappa coefficients were in the range moderate to substantial $(0.41-0.80)$. The ICC for the aggregated scores for awareness of cancer symptoms and risk factors for cancer were 0.80 and 0.75 , respectively.

The sub-group analyses of the two age strata showed a similar pattern of agreement as that seen for the combined analysis. However due to more homogeneity in the response categories for the oldest age group, the kappa coefficients and the ICCs were generally lower for this group.

\section{Discussion}

The translation and pilot-test procedures resulted in a final version of the Danish $A B C$ measure that was found to be conceptually equivalent to the English $\mathrm{ABC}$ measure and that was accepted by the target group. However, evaluation of the data quality showed that the amount of respondents answering 'don't know' was high (above 3\%) for 16 out of 48 items. It is an ongoing debate of whether to include a midpoint or neutral response in measures [9]. The $\mathrm{ABC}$ measure has no midpoint response and therefore 'don't know' may have been used by respondents when the other response options did not fit their answers 
Table 2 Factor loadings of the items in the ABC measure based on EFA for each individual subscale (the loadings in bold are advocated as the final structure of the EFA)

\begin{tabular}{ll}
\hline Subscale and items & Factor loadings \\
\cline { 2 - 2 } & Factor 1 Factor \\
\hline Anticipated patient interval for healthcare seeking & \\
Q5. A persistent cough & $\mathbf{0 . 6 4 1}$ \\
Q6. Rectal bleeding & 0.581 \\
Q7. Any breast changes & \\
Q8. Abdominal bloating & $\mathbf{0 . 6 0 9}$ \\
Awareness of cancer symptoms & $\mathbf{0 . 6 4 6}$ \\
Q9. Unexplained lump or swelling & \\
Q10. Persistent unexplained pain & $\mathbf{0 . 5 7 5}$ \\
Q11. Unexplained bleeding & $\mathbf{0 . 6 1 0}$ \\
Q12. Persistent cough or hoarseness & $\mathbf{0 . 5 9 4}$ \\
Q13. Change in bowel or bladder habits & $\mathbf{0 . 7 1 3}$ \\
Q14. Persistent difficulty in swallowing & $\mathbf{0 . 6 3 7}$ \\
Q15. Change in the appearance of a mole & $\mathbf{0 . 6 9 6}$ \\
Q16. Sore that does not heal & $\mathbf{0 . 6 0 5}$ \\
Q17. Unexplained night sweats & $\mathbf{0 . 5 7 2}$ \\
Q18. Unexplained weight loss & $\mathbf{0 . 5 1 5}$ \\
Q19. Unexplained tiredness & $\mathbf{0 . 7 1 3}$ \\
\end{tabular}

Anticipated barriers for healthcare seeking

Q24. I would be too embarrassed

Q25. I would be worried about what the doctor might find

Q26. I would be worried about wasting the doctor's time

0.379

Q27. I am too busy to make time to go to the doctor

Beliefs about cancer

Q28. People with cancer can expect to continue with normal activities

Q29. Most cancer treatment is worse than the cancer itself

0.410

Q30. Not want to know if I have cancer

0.533

Q31. Cancer can often be cured

0.708

Q32. Going to the doctor as quickly as possible could increase the chances of surviving

Q33. A diagnosis of cancer is a death sentence

0.431

$0.451 \quad(\mathbf{0 . 3 1 2})$

Beliefs about breast cancer screening ${ }^{a}$

QM4. Breast cancer screening is only necessary if I have symptoms

QM5. Breast cancer screening could reduce my chances of dying from breast cancer

0.605

Beliefs about bowel cancer screening

QM6. So worried about what might be found at bowel cancer screening, that I would prefer not to do it

QM7. Bowel cancer screening is only necessary if I have symptoms

QM8. Bowel cancer screening could reduce my chances of dying from bowel cancer

Awareness of risk factors for cancer 
Table 2 Factor loadings of the items in the ABC measure based on EFA for each individual subscale (the loadings in bold are advocated as the final structure of the EFA) (Continued)

$\begin{array}{ll}\text { QN2. Exposure to passive smoking } & \mathbf{0 . 5 7 4} \\ \text { QN3. Drinking more than } 1 \text { unit of alcohol a day } & \mathbf{0 . 5 2 1} \\ \text { QN4. Eating less than } 5 \text { portions of fruit and vegetables a day } & \mathbf{0 . 5 3 5} \\ \text { QN5. Eating red or processed meat once a day or more } & \mathbf{0 . 4 8 3} \\ \text { QN6. Being obese } & \mathbf{0 . 5 3 7} \\ \text { QN7. Getting sunburnt more than once as a child } & \mathbf{0 . 4 4 2} \\ \text { QN8. Being over } 70 \text { years old } & \mathbf{0 . 4 2 8} \\ \text { QN9. Having a close relative with cancer } & \mathbf{0 . 3 4 9} \\ \text { QN10. Infection with HPV, Human Papillomavirus } & \mathbf{0 . 4 6 8} \\ \text { QN11. Not doing much physical activity } & \mathbf{0 . 5 8 3} \\ \text { QN12. Using a solarium } & \mathbf{0 . 4 3 9} \\ \text { QN13. Exposure to ionising radiation from, for example, radioactive } & \mathbf{0 . 4 0 6} \\ \text { materials, x-rays } \text { r radon } & \end{array}$

Table 3 Hypothesis testing by known group comparison

\begin{tabular}{|c|c|c|c|c|c|c|}
\hline \multicolumn{2}{|c|}{$\begin{array}{l}\text { Group } 1 \\
\text { Blue-collar } \\
\text { workers } \\
(n=16)\end{array}$} & \multicolumn{2}{|c|}{$\begin{array}{l}\text { Group } 2 \\
\text { Non-medical } \\
\text { academics } \\
(n=21)\end{array}$} & \multicolumn{2}{|c|}{$\begin{array}{l}\text { Group } 3 \\
\text { GP's and } \\
\text { oncologists } \\
(n=19)\end{array}$} & \multirow[t]{2}{*}{$\begin{array}{l}p \\
\text {-value }\end{array}$} \\
\hline$\%$ & (n) & $\%$ & (n) & $\%$ & (n) & \\
\hline 81.3 & (13) & 61.9 & (13) & - & - & 0.285 \\
\hline 12.5 & (2) & 47.6 & (10) & - & - & 0.035 \\
\hline 62.5 & (10) & 81.0 & (17) & - & - & 0.274 \\
\hline 56.3 & (9) & 71.4 & (15) & & & 0.489 \\
\hline- & - & 52.4 & (11) & 100 & (19) & 0.001 \\
\hline - & - & 9.5 & (2) & 57.9 & (11) & 0.002 \\
\hline - & - & 71.4 & (15) & 94.7 & (18) & 0.095 \\
\hline- & - & 47.6 & (10) & 100 & (19) & 0.000 \\
\hline
\end{tabular}

${ }^{a}$ Fischer's exact test. Statistical significance, italics $p$-value $<0.05$

${ }^{\mathrm{b}}$ Response options were yes often, yes sometimes and no, which were dichotomised into yes/no

${ }^{c}$ Response options were strongly disagree, tend to disagree, tend to agree and strongly agree, which were dichotomised into disagree/agree

${ }^{d}$ For ovarian cancer an answer of 3 or 4 out of 10 was coded as correct 


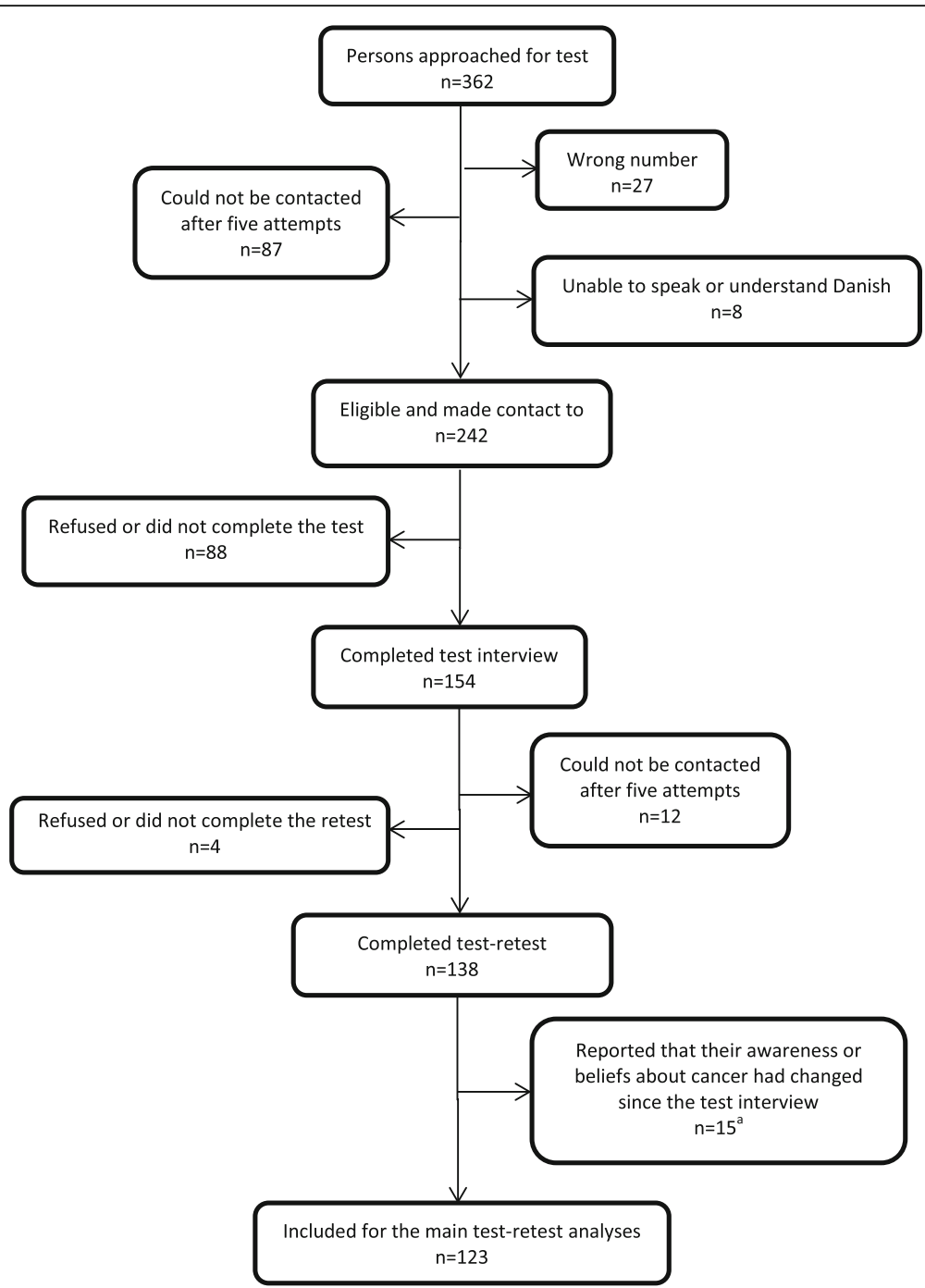

Fig. 2 Flowchart of participants in test-retest. ${ }^{a}$ Respondents were asked to what degree their awareness or beliefs about cancer had changed: To a high degree $(n=1)$, to some degree $(n=1)$ and to a minor degree $(n=13)$

or when they did not understand the item or simply did not know the answer.

Only one item, i.e. change in the appearance of a mole, had limited discriminative value given that $97 \%$ of respondents concurred this item, however, it was included in the $\mathrm{ABC}$ measure because of its importance for face validity [4]. The quantitative content validity assessment showed that items in the $\mathrm{ABC}$ measure adequately reflected and represented the constructs to be measured. However, the hypothesized factor structure of the $\mathrm{ABC}$ measure could not be replicated by a CFA and the iterative analyses put forward a five-factor structure of the $\mathrm{ABC}$ measure. The $\mathrm{ABC}$ measure is an extension of the CAM that was developed and validated in 2007-8 [5]. The amendment of subscales on beliefs about cancer and screening for cancer was made in order for the $A B C$ measure to better reflect important determinants for participation in cancer screening and symptom-triggered healthcare seeking. This also means that the $A B C$ measure is not based on a strong theoretical model and the lack of psychometric support for the proposed factor structure may be explained by this fact [17]. It was, however, reassuring that six out of seven subscales were unidimensional in the EFA on each subscale. The EFA on the subscale 'Beliefs about cancer'suggested two different factors. This finding is not surprising, but in line with a previous study on the Danish ABC measure [27], where we proposed that the positive and negative beliefs about cancer may not be two poles on a unidimensional scale.

The $\mathrm{ABC}$ measure discriminated statistically well between the group of non-medical academics and the group of medical academics but not statistically well between the blue-collar workers and the non-medical academics. When comparing blue-collar workers and 
Table 4 Test-retest reliability of the $A B C$ measure

N $\quad$ Agreement (\%) $\quad$ Expected agreement (\%) $\quad$ Kappa $\quad$ ICC (95\% Cl)

Anticipated patient interval for healthcare seeking

Response options: I would go as soon as I noticed; up to 1 week; over 1 up to 2 weeks; over 2 up to 3 weeks; over 3 up to 4 weeks; more than a month; I would go to another healthcare professional; I would not contact my doctor.
Q5. A persistent cough
Q6. Rectal bleeding
Q7. Any breast changes
Q8. Abdominal bloating

$119 \quad 95.6$

87.3

0.65

$120 \quad 98.5$

92.7

$75 \quad 95.4$

92.0

0.43

$115 \quad 94.2$

80.4

0.70

Awareness of cancer symptoms

Response options: yes and no.

Q9. Unexplained lump or swelling

12290.2

87.7

0.20

Q10. Persistent unexplained pain

$116 \quad 77.6$

62.3

0.41

Q11. Unexplained bleeding

$116 \quad 88.8$

78.1

0.49

Q12. Persistent cough or hoarseness

11984.9

0.58

Q13. Change in bowel or bladder habits

$118 \quad 88.1$

63.9

0.62

Q14. Persistent difficulty in swallowing

Q15. Change in the appearance of a mole

$117 \quad 90.6$

68.6

0.71

Q16. Sore that does not heal

$123 \quad 98.4$

67.9

$-0.01$

$107 \quad 82.2$

98.4

0.49

Q17. Unexplained night sweats

$100 \quad 81.0$

65.4

0.49

Q18. Unexplained weight loss

11995.0

63.4

0.48

Q19. Unexplained tiredness

11586.1

84.6

0.67

65.0

0.60

The total score of cancer symptom awareness

0.80

$(0.72-0.86)$

Anticipated barriers for healthcare seeking

Response options: yes, often; yes, sometimes; no.

Q24. I would be too embarrassed

Q25. I would be worried about wasting the doctor's time

$123 \quad 98.0$

92.6

0.72

$123 \quad 98.0$

91.0

0.77

Q26. I would be worried about what the doctor might find

Q27. I am too busy to make time to go to the doctor

Beliefs about cancer

Response options: strongly disagree; tend to disagree; tend to agree; strongly agree.

Q28. People with cancer can expect to continue with normal activities

Q29. Most cancer treatment is worse than the cancer itself

Q30. Not want to know if I have cancer

Q31. Cancer can often be cured

Q32. Going to the doctor as quickly as possible could increase the

Q33. A diagnosis of cancer is a death sentence

Awareness of 5-year survival from cancer

Response options: $0 ; 1 ; 2 ; 3 ; 4 ; 5 ; 6 ; 7 ; 8 ; 9 ; 10$.

Q34. Out of 10 people diagnosed with bowel cancer, how many do you think would be alive 5 years later? 
Table 4 Test-retest reliability of the ABC measure (Continued)

Q36. Out of 10 people diagnosed with ovarian cancer, how many do you think would be alive 5 years later?

Q37. Out of 10 people diagnosed with lung cancer, how many do you think would be alive 5 years later?

Breast cancer screening behaviour ${ }^{\mathrm{b}}$

Response options: yes; no.

QM1. Breast cancer screening behavior

Bowel cancer screening behaviour ${ }^{c}$

Response options: yes; no.

QM2. Bowel cancer screening behavior

Beliefs about breast cancer screening ${ }^{a}$

Response options: strongly disagree; tend to disagree; tend to agree; strongly agree.

QM3. So worried about what might be found at breast cancer screening, that I would prefer not to do it

QM4. Breast cancer screening is only necessary if I have symptoms

QM5. Breast cancer screening could reduce my chances of dying from breast cancer

98.4

$75 \quad 92.4$

7496.7

Beliefs about bowel cancer screening

Response options: strongly disagree; tend to disagree; tend to agree; strongly agree.

QM6. So worried about what might be found at bowel cancer screening, that I would prefer not to do it

QM7. Bowel cancer screening is only necessary if I have symptoms

QM8. Bowel cancer screening could reduce my chances of dying from bowel cancer

Awareness of growing risk of cancer with age

Response options: 30 year olds; 50 year olds; 70 year olds; people of any age are equally likely to be diagnosed with cancer.

Q38. Growing risk of cancer with age

Awareness of risk factors for cancer

Response options: strongly disagree; tend to disagree; tend to agree; strongly agree.

QN1. Smoking

QN2. Exposure to passive smoking

QN3. Drinking more than 1 unit of alcohol a day

QN4. Eating less than 5 portions of fruit and vegetables a day

QN5. Eating red or processed meat once a day or more

QN6. Being obese

QN7. Getting sunburnt more than once as a child

QN8. Being over 70 years old

QN9. Having a close relative with cancer

QN10. Infection with HPV, Human Papillomavirus

QN11. Not doing much physical activity

QN12. Using a solarium

QN13. Exposure to ionising radiation from, for example, radioactive materials, $x$-rays or radon

The total score of cancer symptom awareness

$\begin{array}{llll}121 & 97.0 & 95.1 & 0.38\end{array}$

$\begin{array}{lll}116 & 87.9 & 70.8\end{array}$

0.36

88.6

(1)


Table 4 Test-retest reliability of the $A B C$ measure (Continued)

Self or someone close with cancer

Response options: yes, respondent; yes, someone close; yes, both self and someone close; yes, but would prefer not to say who; no.

Q3. Self or someone close with cancer

Self-rated health

Response options: very good; good; fair; poor; very poor.

Q20. Self-rated health

Access to a doctor

Response options: very difficult; somewhat difficult; somewhat easy; very easy.

Q21. Access to a doctor

Response options: yes; no.

\section{Q22. Current smoker}

Q23. Former smoker

Weighted kappa computed for women only

${ }^{b}$ Kappa computed for women $\geq 50$ years old

'Kappa computed for men and women $\geq 50$ years old

non-medical academics three of four hypotheses tested differed in the expected direction. However, it was surprising that $80 \%$ of the blue-collar workers were aware that unexplained bleeding could be a warning sign for cancer compared to only $60 \%$ of the academics. Validation is a continuous process and more research is needed to discover whether the $A B C$ measure is poor at discriminating between various non-medical educational groups concerning awareness of cancer symptoms in a Danish population.

Similar to the generic and several cancer specific versions of the CAM which have been developed and validated [5, 22-24, 28], the Danish version of the $\mathrm{ABC}$ measure met accepted psychometric criteria for test-retest reliability. The CAM studies generally found higher values for test-retest and this may among others be due to the fact that all studies except one [28] used the mean of each subscale and Pearson's correlation, which is not a very stringent parameter to assess test-retest reliability [9]. In our study, respondents were excluded from the test-retest analysis if they indicated a transition of awareness and beliefs about cancer. However, there may have been some unknowingly learning effects, as the aggregated score was higher for both awareness about cancer symptoms and risk factors in the retest. Taking this into account and the fact that even measurement of the most stable factors can be affected by fatigue, motivation and distraction [29] it is sufficient that the majority of the items had an agreement of more than $90 \%$.
The major strength of this study is the systematic way of evaluating the measurement properties of the $A B C$ measure by applying several of the quality criteria for good psychometric properties developed by de Vet et al. [9].

The study also has some limitations which should be noted. First, the data of the 3000 respondents who participated in the nationwide survey was collected in mid-2011. However, data for the content validity assessment, knowngroup comparison and test-retest were collected afterwards. Thus, results from these analyses have not been used to refine the Danish $\mathrm{ABC}$ measure.

Further, in respect to the known group comparison it is a limitation that the three groups differed on other indicators (age, marital status and experience of cancer) than educational level and medical proficiency as we cannot dismiss that this has affected the results. Also, it would have been preferable to have included hypotheses about all items in each construct together with expected magnitudes of the differences for the outcomes and to include discriminative hypotheses between the groups in relation to for example 'Beliefs about cancer' and 'Beliefs about screening for cancer'. However, this was hampered by lack of previous studies providing results on the differences in proportions for outcomes on cancer awareness and lack of pre-existing measures on beliefs about cancer in the literature, respectively [4]. Lastly, data for the known-group comparison was collected in two rounds (November 2012-March 2013 and November 2013-January 2014). The reason was that we had some difficulties in recruiting participants and data collection was put on hold while a Danish cancer awareness campaign was running (March- 
April 2013) [30]. The two-round data collection was not ideal, but we believe that the interval of about six months between the campaign and the second round of data collection was adequate in order for the results of the known group comparison not to be affected.

\section{Conclusion and perspectives}

The Danish version of the Awareness and Beliefs about Cancer measure appears to be a useful measurement for assessing the Danish population's awareness and beliefs about cancer. It was accepted and understood by the target group and it met accepted measurement criteria for content validity and test-retest reliability. However, this study also showed some areas in which it can be improved when used in a general population of Danish adults. Hence, future studies may further explore the factorial structure of the $\mathrm{ABC}$ measure and should focus on improving the response categories in order to improve the data quality of the measure.

\section{Additional file}

Additional file 1: Response distributions for all 48 items in the Danish $A B C$ measure. This file contains information on the response distribution for each item together with information on non-response and the percentage of respondents answering 'don't know' for each item. (PDF 109 kb)

\section{Abbreviations}

ABC: Awareness and Beliefs about Cancer; CAM: Cancer Awareness Measure; CFA: Confirmative Factor Analysis; CFI: Comparative fit index; CVI: Content validity index; EFA: Exploratory Factor Analysis; GP: General practitioner; ICBP: International Cancer Benchmarking Partnership; ICC: Intraclass correlation coefficient; RMSEA: Root mean square error of approximation; TLI: Tucker-Lewis Index; UK: United Kingdom

\section{Acknowledgements}

In memory of Professor Jane Wardle (1950-2015) for her essential contribution to this study and the ICBP Module 2 in general.

\section{Funding}

The study was supported financially by the Danish Cancer Society, the Novo Nordisk Foundation, the Faculty of Health at Aarhus University, the Tryg Foundation (J. no. 7-11-1339), the Danish Health Authority and the Research Centre for Cancer Diagnosis in Primary Care (CaP). The funding sources had no involvement in the study design, data collection and analysis, writing of the manuscript or decision regarding publication.

\section{Availability of data and materials}

The data that support the findings of this study are available from the corresponding author on reasonable request.

\section{Authors' contributions}

LH, AFP, CNW and PV conceived the study and its design. LH acquired the data. $\mathrm{LH}$ and $\mathrm{AHC}$ performed the statistical analyses. All authors participated in interpretation of data. LH drafted the manuscript and all authors reviewed drafts of the manuscript, rewrote sections, offered critical comments and approved the final version of the manuscript.

\section{Competing interests}

The authors declare that they have no competing interests.

\section{Consent for publication}

Not applicable.

\section{Ethics approval and consent to participate}

Verbal consent was obtained from each participant before interviewing using the Awareness and Beliefs about Cancer measure. All participation was voluntary and the participants were informed that they could freely withdraw consent at any time. The study was approved by the Danish Data Protection Agency (J. no.2011-41-6237) and the Danish Health Authority. In accordance with the Central Denmark Region Committees on Biomedical Research Ethics, the study needed no further approval (Report no. 128/2010).

\section{Publisher's Note}

Springer Nature remains neutral with regard to jurisdictional claims in published maps and institutional affiliations.

\section{Author details}

${ }^{1}$ Research Centre for Cancer Diagnosis in Primary Care (CaP), Research Unit for General Practice, Department of Public Health, Aarhus University, Bartholins Allé 2, 8000 Aarhus C, Denmark. ${ }^{2}$ Section for General Medical Practice, Department of Public Health, Aarhus University, Bartholins Allé 2, 8000 Aarhus C, Denmark. ${ }^{3}$ Department of Oncology, Aarhus University Hospital, Noerrebrogade 44, 8000 Aarhus C, Denmark.

Received: 8 September 2016 Accepted: 19 April 2017

Published online: 26 April 2017

\section{References}

1. Coleman MP, Gatta G, Verdecchia A, Esteve J, Sant M, Storm H, et al. EUROCARE-3 summary: cancer survival in Europe at the end of the 20th century. Ann Oncol. 2003;14 Suppl 5:128-49.

2. Berrino F, De Angelis R, Sant M, Rosso S, Bielska-Lasota M, Coebergh JW, et al. Survival for eight major cancers and all cancers combined for European adults diagnosed in 1995-99: results of the EUROCARE-4 study. Lancet Oncol. 2007:8(9):773-83.

3. Coleman MP, Forman D, Bryant H, Butler J, Rachet B, Maringe C, et al. Cancer survival in Australia, Canada, Denmark, Norway, Sweden, and the UK, 1995-2007 (the International Cancer Benchmarking Partnership): an analysis of population-based cancer registry data. Lancet. 2011;377(9760):127-38.

4. Simon AE, Forbes $\sqcup$, Boniface D, Warburton F, Brain KE, Dessaix A, et al. An international measure of awareness and beliefs about cancer: development and testing of the ABC. BMJ Open. 2012. doi:10.1136/bmjopen-2012-001758.

5. Stubbings S, Robb K, Waller J, Ramirez A, Austoker J, Macleod U, et al. Development of a measurement tool to assess public awareness of cancer. Br J Cancer. 2009;101 Suppl 2:13-7.

6. McCaffery K, Wardle J, Waller J. Knowledge, attitudes, and behavioral intentions in relation to the early detection of colorectal cancer in the United Kingdom. Prev Med. 2003;36(5):525-35.

7. Environics Research Group. Cancer prevention - attitudes, awareness and behaviours - a national survey of canadians. Ontario: Environics Research group Limited; 2008.

8. Paul C, Girgis A, Wakefield M, Greenbank S, Beckman K, Slevin WWT, et al. Cancer-related knowledge and practices: recommended survey items. Version 1. Newcastle: The Public Health Committee of the Cancer Council Australia; 2006.

9. de Vet HCW, Terwee CB, Mokkink LB, Knol DL. Measurement in medicine: a practical guide. Cambridge: Cambridge University Press; 2011.

10. Terwee CB, Bot SD, de Boer MR, van der Windt DA, Knol DL, Dekker J, et al. Quality criteria were proposed for measurement properties of health status questionnaires. J Clin Epidemiol. 2007;60(1):34-42.

11. Hvidberg L, Pedersen AF, Wulff CN, Vedsted P. Cancer awareness and socioeconomic position: results from a population-based study in Denmark. BMC Cancer. 2014. doi: 10.1186/1471-2407-14-581.

12. Statistics Denmark. 2016. About us. http://www.dst.dk/en/OmDS. Accessed 16 Apr 2017.

13. Clark LA, Watson D. Constructing validity: basic issues in objective scale development. Psychol Assess. 1995;7(3):309.

14. Polit DF, Beck CT, Owen SV. Is the CVI an acceptable indicator of content validity? Appraisal and recommendations. Res Nurs Health. 2007;30(4):459-67.

15. Lynn MR. Determination and quantification of content validity. Nurs Res. 1986;35(6):382-85.

16. Waller J, McCaffery K, Wardle J. Measuring cancer knowledge: comparing prompted and unprompted recall. Br J Psychol. 2004;95(Pt 2):219-34. 
17. Brown TA. Confirmatory factor analysis for applied research. 2nd ed. New York: The Guilford Press; 2015.

18. Floyd JF, Widaman KF. Factor analysis in the development and refinement of clinical assessment instruments. Psychol Assess. 1995;7(3):286-99.

19. Muthén LK, Muthén BO. Mplus User's Guide. 7th Ed. Los Angeles: Muthén \& Muthén; . 1998-2015. 2015.

20. Robb K, Stubbings S, Ramirez A, Macleod U, Austoker J, Waller J, et al. Public awareness of cancer in Britain: a population-based survey of adults. Br J Cancer. 2009;101 Suppl 2:18-23.

21. Redeker C, Wardle J, Wilder D, Hiom S, Miles A. The launch of Cancer Research UK's 'Reduce the Risk' campaign: baseline measurements of public awareness of cancer risk factors in 2004. Eur J Cancer. 2009;45(5):827-36.

22. Power E, Simon A, Juszczyk D, Hiom S, Wardle J. Assessing awareness of colorectal cancer symptoms: Measure development and results from a population survey in the UK. BMC Cancer. 2011. doi: 10.1186/ 1471-2407-11-366.

23. Simon AE, Juszczyk D, Smyth N, Power E, Hiom S, Peake MD, et al. Knowledge of lung cancer symptoms and risk factors in the U.K.: development of a measure and results from a population-based survey. Thorax. 2012;67(5):426-32.

24. Simon AE, Wardle J, Grimmett C, Power E, Corker E, Menon U, et al. Ovarian and cervical cancer awareness: development of two validated measurement tools. J Fam Plann Reprod Health Care. 2012;38(3):167-74.

25. Landis JR, Koch GG. The measurement of observer agreement for categorical data. Biometrics. 1977;33(1):159-74.

26. Shrout PE, Fleiss JL. Intraclass correlations: uses in assessing rater reliability. Psychol Bull. 1979;86(2):420-28.

27. Hvidberg L, Wulff CN, Pedersen AF, Vedsted P. Barriers to healthcare seeking, beliefs about cancer and the role of socio-economic position. A Danish population-based study. Prev Med. 2015;71:107-13.

28. Linsell L, Forbes $L$, Burgess C, Kapari M, Thurnham A, Ramirez AJ. Validation of a measurement tool to assess awareness of breast cancer. Eur J Cancer. 2010:46(8):1374-81.

29. Altmaier EM, Hansen JC. The Oxford handbook of counseling psychology. Oxford: Oxford University Press; 2012

30. The Danish Health Authority. "Rigtige mænd går til lægen": Om kampagnen [In Danish]. 2013. https://www.sst.dk/da/kampagner/rigtige-maend-gaar-tillaegen/om-kampagnen. Accessed 16 Apr 2017.

\section{Submit your next manuscript to BioMed Central and we will help you at every step:}

- We accept pre-submission inquiries

- Our selector tool helps you to find the most relevant journal

- We provide round the clock customer support

- Convenient online submission

- Thorough peer review

- Inclusion in PubMed and all major indexing services

- Maximum visibility for your research

Submit your manuscript at www.biomedcentral.com/submit

) Biomed Central 